\title{
Inclusão e linguagem nos anos iniciais do ensino fundamental
}

\author{
Rogério Drago \\ Universidade Federal do Espírito Santo
}

\section{Resumo}

0 artigo objetiva discutir, com base em pesquisa realizada com crianças com deficiência mental causada pela Síndrome de Down, algumas possibilidades de trabalho com a linguagem oral e escrita pela via de outras ferramentas - música, pintura, teatro e fotografia - para o trabalho docente na escola junto a essas crianças que ingressam no ensino fundamental. São exploradas ferramentas que contribuiriam para a garantia de outro modo de se trabalhar leitura, escrita, percepção, emoção, entre outras características linguísticas próprias das crianças que saem da educação infantil e que podem perder-se diante do engessamento de práticas que o ensino fundamental pode impor.

Palavras-chave: Inclusão. Ensino fundamental. Deficiência mental. Linguagens. 


\section{Inclusion and language in the early years of elementary school}

The article aims to discuss, based on a study of children with mental disabilities caused by Down syndrome, some possibilities for working with oral and written language, using other tools - music, painting, theater and photography - for teachers' work with these children in elementary school. We explore some tools that would help guarantee another way of working with reading, writing, perception, emotion, among other linguistic characteristics of children as they leave kindergarten, which can be lost when they are submitted the inflexible practices often imposed in elementary school.

Keywords: Inclusion. Elementary School. Mental Dissabilities. Languages.

\section{Inclusión y el lenguaje en los primeros años de escuela primaria}

El estudio pretende analizar, desde una investigación de niños con retraso mental causado por el síndrome de Down, algunas de las posibilidades de trabajar con el lenguaje oral y escrito a través de otras herramientas - música, pintura, teatro y fotografía - para trabajo de los profesores de la escuela primaria donde estos niños ingresan. Se analizan algunas herramientas que ayudan a garantizar otra forma de trabajar la lectura, la escritura, la percepción, la emoción, entre otras características lingüísticas de hijos fuera del jardín de infantes y que pueden perderse ante la inmovilización de las prácticas que la escuela primaria puede imponer.

Palabras clave: Inclusión. La escuela primaria. Deficiencia Mental. Lenguaje. 


\section{Introdução}

Pensar a proposição de ações pedagógicas com vistas à inclusão total do aluno com algum tipo de comprometimento físico, mental ou sensorial é ter a chance de, mais do que revelar a sua realidade, destacar a necessidade de se ter/desenvolver um processo educacional coerente com uma educação democrática, que quebre barreiras tradicionais impostas pela sociedade que tenta determinar, a todo o momento, quem pode e quem não pode aprender. Uma outra forma de educação se dá em espaços que primam pela qualidade, que têm projetos pedagógicos voltados para o desenvolvimento de uma educação de qualidade em espaços de qualidade, já que

As escolas de qualidade são espaços educativos de construção de personalidades humanas autônomas, críticas, espaços onde crianças e jovens aprendem a ser pessoas. Nesses ambientes educativos, ensinam-se os alunos a valorizar a diferença pela convivência com seus pares, pelo exemplo dos professores, pelo ensino ministrado nas salas de aula, pelo clima socioafetivo. [...] (Mantoan, 2003, p. 63-64).

A inclusão escolar é uma realidade e, como tal, merece ser encarada de forma contextualizada no cotidiano escolar. A proposta de uma educação inclusiva é muito maior do que somente matricular a criança na escola comum. Na verdade, implica dar outra/nova lógica à escola, transformando suas práticas, suas relações interpessoais, a formação dos docentes e demais profissionais, e seus conceitos, pois a inclusão é um conceito que emerge da complexidade e, como tal, exige o reconhecimento e a valorização de todas as diferenças que contribuiriam para um novo modo de organização do sistema educacional (Drago, 2011a). Entender que existem barreiras que precisam ser transpostas, que métodos e técnicas de ensino precisam ser revistos e que o ensino coletivo pode ser um caminho interessante para o sucesso da inclusão resulta na possibilidade de o processo inclusivo deixar de ser algo apregoado pela legislação e passar a ser parte do dia a dia escolar e social das pessoas que hoje ainda estão fora da escola - ou, ainda, daqueles que estão na escola, mas ainda não fazem parte dela como sujeito ativo, como consta na história da educação especial.

Nesse sentido, este artigo, que faz parte de uma pesquisa intitulada "Inclusão, práticas pedagógicas e atendimento educacional especializado a alunos com deficiência no ensino fundamental", tem por objetivo discutir como se vem dando o processo de escolarização de crianças com deficiência mental causada pela Síndrome de Down que chegam aos anos iniciais do ensino fundamental de nove anos, tendo como foco as práticas docentes cotidianas para o trabalho com a linguagem oral e escrita. Trata-se de um estudo qualitativo, baseado na perspectiva do estudo de caso 
participativo junto a uma turma de alunos do primeiro ano do ensino fundamental que possuía uma criança com Síndrome de Down'. Essa criança saiu da educação infantil em 2010, com cinco anos de idade, para frequentar o ensino fundamental de nove anos, numa escola pública municipal de Vitória.

Num primeiro momento, o artigo apresenta algumas reflexões acerca da inclusão de pessoas com deficiência, transtornos globais do desenvolvimento e altas habilidades/superdotação na escola comum; da linguagem como função psicológica que diferencia os homens dos outros animais, fazendo com que o ser humano se constitua na e pela linguagem; e do ensino fundamental como nível de ensino obrigatório a todas as crianças a partir de seis anos de idade.

Em seguida, apresentamos alguns dados coletados ao longo da pesquisa. Esses dados nos permitem considerar a importância de o professor refletir sobre sua prática e de utilizar outros materiais em sala de aula, com objetivos claros e planejamento adequado a sujeitos concretos. Dessa maneira, o docente tem a chance de obter maior sucesso com seus alunos, independentemente de quaisquer características físicas, mentais e sensoriais que apresentem.

\section{Sobre inclusão escolar de pessoas com deficiência}

A inclusão de crianças nas salas comuns da educação básica é um processo que vem sendo construído há muitos anos no cenário internacional, com o desenvolvimento de ações variadas inseridas em contextos históricos e sociais específicos e com foco no processo educativo em instituições especializadas e comuns de atendimento, como mostram estudos de Mazzotta (2001) e Januzzi (2006). No Brasil, o trabalho com pessoas com deficiência tem início no século $X I X$, quando no reinado de $D$. Pedro II se assiste à fundação do Imperial Instituto dos Meninos Cegos (1854) e do Imperial Instituto dos Meninos Surdos (1857). Em relação ao deficiente mental, esse atendimento permanece com caráter médico-terapêutico até meados do século XX. Porém, no contexto da escola comum, esse público passa a ter maior acesso somente a partir da promulgação da Lei de Diretrizes e Bases da Educação Nacional (LDB), Lei no 9.394, de 1996, que estabelece uma série de garantias às pessoas com deficiência, inclusive a matrícula nas escolas comuns.

Entretanto, não obstante o fato de a LDB estabelecer o acesso e a permanência, na escola comum, das pessoas com deficiência, algumas dessas pessoas ainda enfrentam

1. A Síndrome de Down é uma síndrome causada por um “acidente" cromossômico, sem causa específica, que causa alguns comprometimentos aos sujeitos que a possuem. Entre esses comprometimentos, pode-se citar a deficiência mental, problemas na fala e problemas cardiovasculares. 
uma série de problemas quanto à efetivação de sua matrícula e permanência na escola. Temos percebido que, entre o grupo de pessoas com deficiência (mental, visual, auditiva, entre outras), as que enfrentam mais barreiras em relação à inclusão nas salas de aula comuns, em todos os níveis de ensino, são aquelas que apresentam deficiência mental e transtornos globais do desenvolvimento, o que inclui os alunos com Síndrome de Down, Autismo, Asperger e Willians, entre outras (Drago, 2005).

A inclusão de pessoas com deficiência, transtornos globais do desenvolvimento ou altas habilidades/superdotação nas salas comuns da escola básica, conforme preconizam alguns documentos legais (Brasil, 2008; 2009) e alguns dos principais estudiosos nacionais da área (Prieto, 2006; Mendes, 2002; Baptista, 2006; Victor, 2010; 2011; Beyer, 2006; entre outros), é um processo que ganha força a partir da Declaração de Salamanca, em 1994, e se estende até hoje como uma bandeira que tem por objetivo garantir a premissa de que a educação é um direito de todos e dever do Estado. Esse 'todos' envolve todas as pessoas que estejam fora da escola ou dela e de seus processos alijados.

A esse respeito, Beyer ressalta que

A educação inclusiva caracteriza-se como um novo princípio educacional, cujo conceito fundamental defende a heterogeneidade na classe escolar, como situação provocadora de interações entre crianças com situações pessoais as mais diversas. Além dessa interação, muito importante para o fomento das aprendizagens recíprocas, propõem-se e busca-se uma pedagogia que se dilate frente às diferenças do alunado. (Beyer, 2006, p. 73)

A literatura atual que trata da educação da pessoa com deficiência tem enfatizado que existem ainda muitas armadilhas para que a escola inclusiva deixe de ser mera proposição e passe a existir de verdade. Entre essas armadilhas podemos destacar duas: as práticas supostamente inclusivas que muitas vezes excluem as pessoas com deficiência do contexto educacional e os materiais utilizados para o desenvolvimento da ação pedagógica. Tais práticas e materiais muitas vezes simplificam os conteúdos curriculares, fazendo com que à pessoa com deficiência seja criado um pseudocurrículo, ou outro currículo, diferente, minimizado, quando se pensa é um mesmo currículo com variadas propostas de trabalho. Ou seja, o que nos importa é o modo, os procedimentos, as ferramentas que esse sujeito utiliza para se apropriar dos conhecimentos produzidos social e culturalmente.Quando pensamos na proposta de uma escola inclusiva, que leve em consideração as particularidades, possibilidades e peculiaridades de cada sujeito como mola propulsora da ação pedagógica, devemos ter em mente que a inclusão requer a quebra de cristalizações educacionais que fazem com que tantas pessoas sejam deixadas à margem do conhecimento escolar por apresentarem 
características que, muitas vezes, destoam daquilo que convencionalmente se tem como normal, acomodado, cristalizado. A inclusão pressupõe o contrário, isto é, existe a proposição e o reconhecimento de todas as diferenças que culminariam com um novo modo de organização do sistema educacional que vai muito além da mera escola em si, sem subdivisões sem guetos. Esse entendimento de escola inclusiva requer, necessariamente, que se efetive no contexto educacional a ideia de ambientes dinâmicos, ricos, envolventes para estimular todos os alunos. Logo, o que se tem em mente é que a escola comum seja capaz de dar conta de todas as especificidades e peculiaridades de todos os seus sujeitos de modo que estes, por sua vez, não sejam confinados em salas especiais no interior de escolas que se dizem inclusivas.

A escola inclusiva direciona-se para um ensino que, além de reforçar os mecanismos de interação solidária e os procedimentos cooperativos, auxilia o ser humano a se ver e se perceber como parte de um todo que independe de suas características físicas. Temos observado em vários estudos (Drago, 2011a; 2011b; Capellini, 2010; 2011 ; Victor, 2010; 2011) que a proposta de educação inclusiva, que vê a criança como sujeito da ação pedagógica, tem se efetivado com mais ênfase na educação infantil. Assim, questionamos: qual trabalho tem sido realizado com a linguagem oral e escrita no ensino fundamental de nove anos, que agora recebe crianças de seis anos? Que cenário vem se desenhando em relação á formação dessas crianças?

\section{Sobre o ensino fundamental de nove anos}

O ensino fundamental de nove anos aparece no cenário educacional brasileiro na década de 1990, quando da promulgação da LDB lei n 9.394/96 que sinalizava, de modo muito superficial, a possibilidade de um ensino fundamental com início aos 6 anos de idade. Porém, isso só se efetiva a partir de 2005,com o parecer CNE/CEB nº 06 , que estabelece normas nacionais para a ampliação do ensino fundamental para 9 anos, e da lei $n^{0} 11.114 / 2005$, que determinou a obrigatoriedade do início do ensino fundamental aos seis anos de idade a partir de 2006. Nesse processo, em fevereiro de 2006, temos a Lei n 11.272, que altera a redação dos artigos 29, 30, 32 e 87 da LDB, instituindooficialmente o ensino fundamental de 9 anos, com matrícula a partir dos 6 anos de idade, já nas classes de alfabetização.

Essa entrada de crianças de seis anos no ensino fundamental de 9 anos trouxe grandes dúvidas acerca dos modos de organização do ensino, das estratégias de aprendizagem e desenvolvimentos, do modo como as escolas de ensino fundamental estavam organizadas em relação aos aspectos tempo-espaço, entre outros que precisariam ser discutidos no sentido de receber esse novo público que teria 
diminuído o seu tempo de permanência na educação infantil. Para tanto, em 2006, o MEC lançou um documento intitulado "Ensino fundamental de nove anos: orientações para a inclusão da criança de seis anos de idade" (Brasil, 2006). Tal documento salienta os modos próprios de se trabalhar com a criança, porém sem tratar em momento algum da criança com deficiência, que sai da educação infantil e chega ao ensino fundamental, salientando as singularidades, possibilidades, complexidades e particularidades dessa faixa etária e do trabalho pedagógico a elas destinado, daí a necessidade de se pensar ações que contemplem a educação da criança de modo que ela se aproprie do conhecimento sem deixar de lado sua infância e condição de criança.

Nesse sentido, outro ponto a ser destacado é que

a implantação de uma política de ampliação do ensino fundamental de nove anos de duração exige tratamento político, administrativo e pedagógico, uma vez que o objetivo de um maior número de anos no ensino obrigatório é assegurar a todas as crianças um tempo mais longo de convívio escolar com maiores oportunidades de aprendizagem. (Brasil, 2006, p. 7)

Esse tempo mais longo precisa ser revestido de novas formas de se pensar e realizar o aprendizado escolar. Para Vigotski (1991, p. 93), “o aprendizado escolar é mais do que a aquisição de capacidade para pensar; é a aquisição de muitas capacidades especializadas para pensar sobre várias coisas". Assim, entendemos que a criança com ou sem deficiência, ao estar na escola comum, nos anos iniciais do ensino fundamental, precisa entrar em contato com o maior número possível de atividades e objetos que possam enriquecer seu arcabouço de informações. Essa gama de informações pode ser adquirida por meio da apropriação e exercício da linguagem em suas mais variadas manifestações.

\section{Algumas considerações sobre a linguagem}

Sabe-se que a linguagem assume diferentes contornos e inúmeras possibilidades de ação, como afirmam estudos de Vigotski (2001) e Bakhtin (2003), e que a decodificação de símbolos escritos não pode ser considerada como a única forma de linguagem existente numa sociedade. Além disso, vale destacar que, para Vigotski, a linguagem é a função psicológica superior mais importante dos seres humanos, uma vez que é por meio da linguagem que nos relacionamos conosco mesmos e com os outros, já que a linguagem assume função tanto individual quanto social. E para a criança com deficiência, esse processo assume contornos muito específicos: 
Quando a criança se apropria da linguagem, revelando seu potencial expressivo e criativo, ela rompe com as formas fossilizadas e cristalizadas de seu uso cotidiano, iniciando um diálogo mais profundo entre os limites do conhecimento e da verdade na compreensão do real (Jobim e Souza, 2001, p.159).

Tomando por base o que a autora destaca, é possível compreender que a criança se constitui como sujeito na e pela linguagem. Entretanto, é necessário que ela interprete essa linguagem, ultrapasse a barreira da mera decodificação dos aparatos linguísticos, e dê a sua significação para, assim, reinventar seu repertório cultural na e pela linguagem, pois

[...] a infância é o momento em que a linguagem humana emerge como significação, pois é na fala da criança que acontece a passagem do signo linguístico para a ordem do sentido. (Jobim e Souza, 2001, p. 151)

Temos percebido em vários estudos (Rocha; Kramer, 2011) que muitas das questões que têm como foco os processos de construção/desenvolvimento/apropriação da linguagem oral e escrita pelas crianças com ou sem deficiência, suscitam, no seio do corpo docente e técnico-pedagógico das escolas muitas tensões, contradições e indagações que perpassam, por exemplo, dúvidas acerca dos modos de apropriação da linguagem oral e escrita, se existem requisitos para essa aprendizagem, que lugar a escola ocupa nesse processo. Essas e outras, indefinições que podem fazer com que as crianças com deficiência, por apresentarem maiores dificuldades no alcance desses processos, acabem ficando à margem do ensino comum.

Pensar a leitura e a escrita na educação implica pensar num conjunto de práticas discursivas orais e escritas que façam e/ou possam vir a fazer parte da vida das crianças. Para Bakhtin (1992), a linguagem supõe uma situação de troca social. São sujeitos em interação que produzem enunciados concretos que, por sua vez, são determinados pelas condições reais de enunciação - a situação social mais imediata, que inclui gestos, entoação, vontades, afetos, ditos e não ditos [...] qualquer atividade de linguagem e com a linguagem não pode ser descontextualizada. Linguagem e vida se atravessam mutuamente. As esferas da vida são espaços de produção de linguagem e cada enunciação se atualiza num determinado tempo e espaço em que a vida circula. (Corsino, 2011, p. 246-247)

Nesse sentido, entendemos que o trabalho pedagógico, que tem como foco central o desenvolvimento da linguagem oral e escrita de crianças com deficiência matriculadas nas salas comuns do ensino fundamental, precisa estar pautado no significado da palavra como parte inalienável da ação docente, pois, independente de 
qualquer característica mental, sensorial, física, intelectual, "é fundamental que os textos escritos façam sentido para as crianças e que ler e escrever sejam relevantes e necessários para suas vidas" (Corsino, 2011, p. 246).

Temos observado que diferentes objetos podem ser utilizados e explorados pelo professor para desenvolver o repertório linguístico das crianças com deficiência que agora também chegam mais cedo ao ensino fundamental, fazendo com que se apropriem de modo mais prazeroso da linguagem oral e escrita como sistema organizado e organizador que, para se tornar uma ferramenta simbólica, precisa ser internalizada pelo sujeito (Vigotski, 2001). A partir desse entendimento, a linguagem ganha outra dimensão, assumindo uma característica mais ampla, que ultrapassa a mera decodificação de letras, num processo geralmente mecânico e enfadonho, para assumir a característica de ser algo que alimente o imaginário desse ser, amplie sua capacidade cognitiva, desenvolva seus conhecimentos, possibilite o acesso a diferentes culturas e a diferentes conhecimentos.

Para tanto, algumas ferramentas de enriquecimento do trabalho docente podem auxiliar o professor em sua ação cotidiana, explorando, assim, o desenvolvimento e aprimoramento de atividades linguísticas que objetivam desenvolver a escrita e oralidade através de outros/novos materiais que fazem parte do cotidiano das crianças e que, muitas vezes, permanecem esquecidos pela escola, que se utiliza única e exclusivamente do livro didático como material, desconsiderando, muitas vezes, as reduzidas capacidades de decodificação de crianças com deficiência.

Essas ferramentas encontram eco naquilo que Corsino evidencia em seus estudos, quando afirma que

Vygotsky aponta como pré-história da linguagem escrita os gestos, a brincadeira e o desenho como simbolismos que levam diretamente à linguagem escrita. Para escrever a criança precisa perceber que além dos objetos e situações pode desenhar também a fala. Portanto, dramatizar, brincar e desenhar não podem ser negligenciados nos espaços de Educação infantil já que também participam do processo para se chegar à escrita. (Corsino, 2003, p. 118)

Ao sair de um texto e ir para a expressão plástica e auditiva, como ver uma exposição de quadros, de esculturas, assistir e/ou participar de uma peça teatral, ouvir música, ver fotografias, as crianças com deficiência também desenvolvem suas múltiplas linguagens, ou seja, quando mantêm contato com outras paisagens, outros jardins e outros bosques que não só aqueles de letras, as quais, às vezes, podem ser frias e sem entusiasmo. Isso sem contar com toda a possibilidade de ampliação do repertório artístico cultural, tanto das crianças quanto do próprio 
professor,que muitas vezes sequer abre espaço em sua vida acadêmico-profissional para que essas outras linguagens estejam presentes. 0 docente tem o papel de organizar a ação educativa, logo de possibilitar à criança que entre em contato com o novo, pois

[...] a verdadeira tarefa do educador não consiste em habituar apressadamente a criança a expressar-se na linguagem na linguagem dos adultos, senão em ajudar a elaborar e amadurecer sua própria linguagem literária. (Vigotski, 1996, p. 58)

De acordo com Bakhtin (2003), cada época e cada grupo social têm seu repertório de formas de discurso que funciona como um espelho que reflete e refrata o cotidiano. A palavra escrita, falada, desenhada, registrada, nesse contexto, assume a característica de ser uma das formas de revelação de um espaço no qual os valores fundamentais de uma dada sociedade se explicitam e se confrontam, ao mesmo tempo em que se perpetuam.

A linguagem reveste-se numa forma de concretização do pensamento abstrato, já que o ser humano é o único animal que consegue, de forma consciente, traduzir em símbolos aquilo que pensou. Assim, a linguagem em todas as suas formas é uma ferramenta social importantíssima para a humanização do ser humano, ou seja, para a superação das características meramente biológicas.

A palavra [e a linguagem em sua forma mais ampla] será sempre o indicador mais sensível de todas as transformações sociais, mesmo daquelas que apenas despontam, que ainda não tomaram forma, que ainda não abriram caminho para sistemas ideológicos estruturados e bem formados. (Bakhtin, 2002, p. 41)

Quando escrevemos, desenhamos, registramos algo, estamos imprimindo nossa versão de fatos, imprimimos nossas características, nossa capacidade de sintetizar/ concretizar o pensamento abstrato.Ao pensarmos na escola e no modo como esta se organiza cotidianamente, além de levarmos em conta nossa inserção na escola como docente, pesquisador e aluno, nos perguntamos: por que se dá tão pouca ênfase à arte na educação e no desenvolvimento da linguagem oral, escrita, visual e auditiva? A escola pode ser um lugar de encontro? Encontro de pessoas consigo mesmas, com o mundo e a cultura? Como os materiais pedagógicos que trabalham com a linguagem oral e escrita têm ocupado o seu espaço na escola? Será que as escolas se restringem ao desenvolvimento linguístico apenas em letras/textos escritos, muitas vezes descontextualizados? Essas e outras tantas questões nos conduziram a este estudo que agora descortinamos, ao menos uma parte. 


\section{Inclusão e linguagem: o que nos diz o cotidiano observado}

Como sinalizado na introdução, este estudo é parte de uma pesquisa que teve como objetivo discutir como vem se dando o processo de escolarização de crianças com deficiência mental causada pela Síndrome de Down que chegam aos anos iniciais do ensino fundamental de nove anos, com foco nas práticas docentes cotidianas para o trabalho com a linguagem oral e escrita.

Ao chegarmos à escola para ralização da pesquisa, nos deparamos com a professora² da turma muito preocupada em realizar um trabalho pedagógico com essa criança no sentido de trabalhar a linguagem oral, não só para que esta criança se comunicasse com as demais, mas também para que ela se apropriasse da linguagem como ferramenta humana, porém, sem deixar de lado os conhecimentos escolares das disciplinas de língua portuguesa, matemática, história, geografia, ciências, artes, informática e outras ${ }^{3}$.

Nosso trabalho se deu em duas fases: com a professora uma vez por semana, por dois meses no primeiro semestre de 2011, por meio de grupos de estudo com foco nas práticas desenvolvidas pela professora. Esses grupos de estudo aconteciam durante o horário de planejamento da professora. Após esse tempo, passamos à segunda fase da pesquisa que foi a observação participante em sala de aula, auxiliando a professora no desenvolvimento de suas ações.

Num dos primeiros encontros sugerimos à professora que trabalhasse com essa criança e com as demais a partir de uma proposta lúdica, centrada no trabalho com a linguagem, por entendermos que é na e por meio da linguagem que a criança se apropria da cultura de seu grupo, ao mesmo tempo em que constrói sua identidade como sujeito social. Para tanto, sugerimos que ela buscasse na música, na pintura, na dramatização e na fotografia algumas ferramentas para suscitar o trabalho com os conteúdos propostos pela escola ao mesmo tempo em que trabalhava a linguagem em suas formas mais amplas e diversificadas.

Trabalhamos com a professora alguns aspectos teórico-metodológicos das ferramentas propostas, para que esta profissional pudesse perceber outras/novas possibilidades de ressignificar sua prática docente numa perspectiva inclusiva, inovadora e agradável para todas as crianças, ao mesmo tempo em que a fizesse perceber que ao exercitar a linguagem em todas as suas possibilidades, a criança com Síndrome de Down poderia desenvolver suas funções superiores tipicamente

2. No município de Vitória os professores tanto da educação infantil quanto do ensino fundamental possuem curso superior completo, devida habilitação, como requisito mínimo para assumir suas funções docentes. Possuem também plano de cargos e salários.

3. No município de Vitória as escolas de ensino fundamental têm uma grade curricular ampla, com várias disciplinas, desde o primeiro ano. 
humanas, na medida em que perceberia a língua como ferramenta de ação social e psicológica, afinal, como salienta Vigotski,

[...] a capacidade especificamente humana para a linguagem habilita as crianças a providenciarem instrumentos auxiliares na solução de tarefas difíceis, a superar a ação impulsiva, a planejar uma solução para um problema antes de sua execução e a controlar seu próprio comportamento. Signos e palavras constituem para as crianças, primeiro e acima de tudo, um meio de contato social com outras pessoas. As funções cognitivas e comunicativas da linguagem tornam-se, então, a base de uma forma nova e superior de atividade nas crianças, distinguindo-as dos animais. (Vigotski, 1991, p. 31)

Nesse sentido, considerando a importância da linguagem para o desenvolvimento do ser humano com e sem deficiência, apresentamos à professora as quatro ferramentas propostas para auxiliar no trabalho com essa criança. Partimos da premissa de que a música é uma forma de linguagem e de conhecimento. Ela está presente no cotidiano da criança, que entra em contato muito cedo com a cultura musical. Falando em música, lembramos de ritmo, e ritmo é a marca essencial da poesia. É o que possibilita o acompanhamento musical, que pode ser lido ou ouvido. Ao integrar poesia e música, a canção remete sempre ao conteúdo da letra. Alertamos a professora que ao trabalhar poesias de diversos gêneros, estilos, épocas e culturas, o professor poderá ao mesmo tempo em que se apropria de um conhecimento musical, apresentar obras que despertem o desejo de ouvir e interagir da /na criança. 0 contato com obras musicais pode ser completado com informações relativas ao contexto histórico de sua criação, a época, seu compositor, intérprete, dentre outras informações trazidas tanto pelas crianças quanto pelo professor.

Outra atividade sugerida foi sonorização de histórias, já que o material sonoro trabalha a percepção auditiva, a discriminação e a classificação de sons laltura, duração, intensidade e timbre). As histórias só com imagens são interessantes e adequadas para esse fim, utilizando sons vocais e corporais produzidos por objetos do ambiente, brinquedos sonoros e instrumentos musicais, podem-se acompanhar os contos de fadas, a produção literária infantil, as poesias e também as criações de histórias dos alunos.

Há uma diversidade de sons que podem se fazer presentes, como: um bater de portas, o trotar de cavalos, a água corrente no riacho, o canto dos sapos, enfim, são muitos os elementos que podem estimular a leitura através da música. As cantigas de ninar e as canções de rodas, como, por exemplo, A Linda Rosa Juvenil, Samba lelê, podem servir para resgatar os valores musicais de sua cultura e aproximar os alunos deles.

Por outro lado, não se pode negligenciar outros tipos de música que façam parte da realidade da criança, como por exemplo, o rap, o funk, o pagode, o samba, o 
gospel, dentre outros estilos, pois podem se constituir elementos ímpares para que a criança se veja como parte do processo educacional ao mesmo tempo em que vê sua identidade sendo valorizada, logo, sente-se estimulada a participar do processo de criação como sujeito cultural.

No que tange à pintura, trabalhamos no sentido de que a professora percebesse que as expressões artísticas são formas de linguagem próprias dos seres humanos desde sempre e estão presentes no cotidiano da vida infantil; são, portanto, formas importantes de expressão e comunicação humana. Ao trabalhar com a interpretação de imagens, o professor deve eleger materiais que contemplem a maior diversidade possível e que sejam significativos para seus alunos. Nos planejamentos em conjunto com a professora destacamos que uma atividade fácil de ser trabalhada em sala de aula e que pode trazer ótimos resultados para a leitura e apropriações culturais é a releitura de obras de artes com os mais variados materiais. Ou seja, através da observação de pinturas famosas ou não, a criança pode recriar com materiais diversos (grãos, papel picado, sementes, pó colorido, massa de modelar, barrol esculturas e pinturas re-lidas e re-pensadas. Para tanto, segundo Oliveira (1998, p. 9), “o professor deve oferecer diferentes materiais para a criança trabalhar, tais como lápis, giz, giz de cera, lixa, esponja, escova, cotonetes, massinha, argila, massa caseira, massa de jornal, sementes, barbantes, folhas de árvores, sucata etc."

Salientamos que qualquer tipo de material pode ser usado para a releitura de uma obra, não somente os produtos industrializados, mas também aqueles colhidos ou achados, o que nos leva a pensar na criança caçadora de Walter Benjamin, que dá outra lógica àquilo que nós adultos não conseguimos.

Assumindo esta perspectiva, sugerimos que a professora elaborasse perguntas que instigassem a observação, a descoberta e o interesse do aluno, como: "Do que mais gostou?", "Que instrumentos e meios será que o pintor usou?", "0 que você acha que foi mais difícil para ele fazer"? 0 professor poderá fornecer dados sobre a vida do autor, suas obras, em que época ele viveu, ou mesmo sugerir uma pesquisa mais profunda com os alunos, e, assim, proporcionar o encontro da criança com a leitura da obra de arte, a pesquisa e o conhecimento.

Em relação à dramatização, trabalhamos com a professora no sentido de que ela percebesse que essa atividade é importante, pois permite que as crianças explorem com criatividade todos os materiais existentes dentro e fora da escola, nos quais possam observar diferentes atitudes em diferentes situações, com o objetivo de trabalhar variados comportamentos, emoções, gestos e sentimentos. Destacamos, também, que além das expressões cotidianas, outro material que pode ser usado 
na escola para servir de apoio a dramatizações é a literatura infanto-juvenil, independente do domínio ou não da leitura oral pela criança.

Outra ferramenta sugerida para o incremento da prática docente foi a fotografia. Esse é, sem dúvida, um material que todos têm em casa. Destacamos com a docente que todos gostam de ver e interpretar uma fotografia: o olhar de quem fotografou, 0 que foi fotografado são leituras que vêm a nossa mente quando vemos uma fotografia. Além disso, a fotografia tem o poder de mostrar fatos históricos, culturais e sociais do modo como aconteceram e foram registrados.

Destacamos que muito do desenvolvimento sociocultural e crítico da criança pode ser desenvolvido através de questões com foco na utilização de fotografias como material para o trabalho com a linguagem em todas as suas possibilidades, como: o que você está vendo? 0 que será que eles estão fazendo? Por que será que foram fotografados? Quais roupas estão usando? Será que são parecidas com as nossas? Onde será que eles estão? Será que lá é legal? Onde podemos obter mais informações sobre esse lugar? Será que essa foto foi tirada há muito tempo? Como sabemos disso? Há uma infinidade de questões que, além de serem discutidas, podem ser escritas, representadas, debatidas. Além disso, a fotografia ainda permite que a criança veja e se perceba, ao ser fotografada, como um ser concreto que possui características diferentes das dos outros seres humanos.Diante do exposto cabe salientar que o trabalho desenvolvido junto à professora pesquisada e no contato direto com as crianças com e sem deficiência na sala de aula comum, tento por base o desenvolvimento/envolvimento com as várias linguagens envolvem a literatura, interpretação, cultura e aprendizado revelou que quando a professora passou a privilegiar outras ferramentas para trabalhar a linguagem oral e escrita com as crianças, estas passaram a se envolver mais com o seu cotidiano.

Com o uso de fotografia, música, dramatização e pintura, esse educando com Síndrome de Down pôde se ver e se perceber como sujeito ativo do processo ensinoaprendizado de algo extremamente importante para o exercício da cidadania, ou seja, o desenvolvimento de várias maneiras de se expressar, de enriquecer e de exercitar a linguagem. Percebemos que na medida em que o trabalho docente avançava, essa criança, assim como as demais, aprimorava sua capacidade de realizar uma interpretação que utilizava todos os seus órgãos sensoriais e sua capacidade crítica, tanto na abstração da realidade quanto de conhecimento do mundo que a cercava.

As crianças, na medida em que eram instigadas a trazer fotografias de suas vidas e famílias para serem visualizadas/analisadas/dialogadas por todos; a representar suas ações cotidianas em casa, na rua, na igreja, na escola; ao desenhar e pintar suas ações; ao ouvir/criar/interagir com suas músicas preferidas e conhecer as dos colegas, passaram a se ver e se reconhecer como sujeitos da ação pedagógica. 
Sujeitos ativos, que vivem, respiram, sentem, falam, possuem desejos, medos, alegrias, tristezas, satisfações, insatisfações, que precisam ser trabalhadas na escola, pois levam a criança a se humanizar na medida em que transforma/exercita/ pratica o mundo ao seu redor com/na/pela linguagem. Além disso, acreditamos a partir dos estudos de Vigotski (1991, p. 27), que "o momento de maior significado no curso do desenvolvimento intelectual, que dá origem às formas puramente humanas de inteligência prática e abstrata, acontece quando a fala e a atividade prática, então duas linhas completamente independentes de desenvolvimento, convergem".

0 trabalho com as crianças com e sem deficiência, e no caso deste estudo, das que têm Síndrome de Down, nos anos iniciais do ensino fundamental de nove anos, diante da abreviação do espaço/tempo da educação infantil - que é essencialmente lúdica - precisa revestir-se de um espaço que tenha como foco o trabalho com muitos materiais interessantes para as crianças, materiais como livros, revistas, recortes, colagens, pintura, desenho, vídeos, música, produção de textos, enfim, um trabalho que objetive transformar o processo ensino-aprendizagem em algo que seja ao mesmo tempo interessante e agradável para o professor e para as crianças. Além disso, há que se trabalhar para que a criança, ao mesmo tempo em que se apropria do conhecimento já produzido, produza suas impressões sobre este conhecimento, num processo realmente interativo, dialético e que veja a criança como ser histórico e social que produz cultura, que é sujeito do processo educacional e que também possui/ produz/reproduz a linguagem de seu grupo social, e para tanto precisa exercitar essa linguagem em suas mais variadas possibilidades (Vigotski, 2001; Kramer, 2006).

0 uso de materiais concretos, neste estudo, mostrou-se benéfico para todas as crianças, principalmente a que apresentava deficiência mental causada pela síndrome de Down, pois passou a se comunicar, a interagir com seus pares e, nesse processo, se humanizar. Para o trabalho com as crianças nos anos iniciais do ensino fundamental de nove anos, os recursos trabalhados, passaram a ter uma importância muito grande, pelo fato de que, a criança com Síndrome de Down precisará tocar/ sentir/vivenciar mais o material do que outras crianças. Assim, ter um número muito grande de recursos para o trabalho, como no caso desse estudo que teve como foco a linguagem oral e escrita, desses sujeitos pode levá-los a um melhor desenvolvimento de suas capacidades e, consequentemente, a uma ampliação positiva de suas funções psicológicas superiores (Vigotski, 1991).

No trabalho em conjunto com crianças com deficiência mental em processo de inclusão nos anos iniciais do ensino fundamental e com a professora regente, foi observado que materiais como livros de EVA, livros de tecido, letras em relevo, jogos diversos, objetos em miniatura, teclados de computador, fantoches, papéis coloridos 
e de diferentes texturas, retalhos de tecidos, canetas coloridos, rádio, televisão, pinceis e tintas, jornais, revistas e outros tantos materiais, quando utilizados de modo natural, planejado e com sentido, podem auxiliar o docente em seu trabalho. Ao mesmo tempo, contribuem para que a criança se desenvolva em todas as suas possibilidades e se aproprie da linguagem oral/escrita de modo prazeroso, agradável e com significado, sem que se crie outro currículo, mas com procedimentos diferenciados. Percebemos que a professora, na medida em que assumia essa outra postura diante da leitura e da escrita trabalhava no sentido de que esse processo deveria ter significado para as crianças. Não como algo imposto, mas como algo natural. Ou seja,

Da mesma forma que as crianças aprendem a falar, elas podem aprender a ler e a escrever. Métodos naturais de ensino da leitura e da escrita implicam operações apropriadas sobre o meio ambiente das crianças. Elas devem sentir necessidade do ler e do escrever. (Vigotski, 1991, p. 134)

Em suma, cabe salientar que a criança, com ou sem deficiência, que chega ao ensino fundamental de nove anos é aquela que está imbuída num dado contexto social e cultural anterior à sua existência e que é esse contexto que será lou deveria serl a base da construção de sua identidade e subjetividade, portanto, ao propor um trabalho com várias/outras linguagens para o trabalho com a leitura e a escrita, deve-se ter em mente que

É através dessas linguagens que aprendemos a dar sentido às coisas e a nós mesmos. E esses artefatos são instrumentos didáticos das práticas cotidianas das escolas. Se a escola oferece à criança um ambiente que expresse o respeito e a valorização das características e referências ligadas aos diversos sujeitos [e linguagens] de seu contexto, cumprirá seu papel de formação para a diversidade. (Lima, 2011, p. 153)

Pensar a escola hoje não é mais pensar somente a transmissão de um conteúdo frio e sem vida, vinculado a uma listagem interminável de assuntos a serem trabalhados durante certo período do ano, dar uma prova ao final do bimestre e encher o quadro de atividades enfadonhas e desvinculadas da realidade de alunos e, por que não dizer, de professores também. Assim, concordando com Lima, fica o convite para que os profissionais das escolas reflitam sobre as múltiplas linguagens presentes na escola e que as práticas pedagógicas com vistas à inclusão de sujeitos com deficiência, transtornos globais do desenvolvimento e altas habilidades superdotação se apropriem dessas linguagens no sentido de que este processo seja ressigificado, planejado, rico, atraente, agradável para todos. 


\section{Referências}

BAPTISTA, C. R. Inclusão e escolarização: múltiplas perspectivas. Porto Alegre: Mediação, 2006.

BEYER, H. O. Da integração escolar à educação inclusiva: implicações pedagógicas. In: BAPTISTA, C. R. Inclusão e escolarização: múltiplas perspectivas. Porto Alegre: Mediação, 2006, p. 73-82.

BRASIL. ensino fundamental de nove anos: orientações para a inclusão da criança de seis anos de idade. Brasília: MEC/FNDE, 2006.

- Política Nacional de Educação Especial na Perspectiva da Educação Inclusiva. Brasília: MEC/SEESP, 2008.

. Resolução CNE/CEB 04/2009. Brasília: MEC/SEESP, 2009.

BAKHTIN, M. Estética da criação verbal. São Paulo: Martins Fontes, 2003.

. Marxismo e filosofia da linguagem. 10. ed. São Paulo: Hucitec, 2002.

CAPELLINI, V. L. M. F. 0 ensino colaborativo favorecendo políticas e práticas educativas de inclusão escolar na educação infantil. In: VICTOR, S. L.; DRAGO, R.; CHICON, J. F. (Orgs.). A educação inclusiva de crianças, adolescentes, jovens e adultos: avanços e desafios. Vitória: EDUFES, 2010, p. 83-108.

. Infância e inclusão escolar de crianças com necessidades educacionais especiais. In: VICTOR, S. L.; DRAGO, R.; CHICON, J. F. (Orgs.). Educação especial e educação inclusiva: conhecimentos, experiencias e formação. Araraquara: Junqueira\&Marin, 2011, p. 128-151.

CORSINO, P. Infância, linguagem e letramento: educação infantil na rede municipal de ensino do Rio de Janeiro. 2003. Tese (Doutorado em Educação) - Pontifícia Universidade Católica do Rio de Janeiro, Rio de Janeiro, 2003.

Professoras de educação infantil e suas visões de letramento: tensões da prática. In: ROCHA, E. A. C.; KRAMER, S. Educação infantil: enfoques em diálogo. São Paulo: Papirus, 2011, p. 241-258.

DRAGO, R. Infância, educação infantil e inclusão: um estudo de caso em Vitória. 2005. Tese (Doutorado em Educação) - Pontifícia Universidade Católica do Rio de Janeiro, Rio de Janeiro, 2005.

. Inclusão na educação infantil. Rio de Janeiro: WAK, 2011a.

. Educação infantil e educação inclusiva: um olhar sobre o trabalho com crianças com deficiência. In: ROCHA, E. A. C.; KRAMER, S. Educação infantil: enfoques em diálogo. São Paulo: Papirus, 2011b, p. 259-276.

JANUZZI, G. A Educação do deficiente no Brasil: dos primórdios ao início do século XXI. 2.ed. São Paulo: Autores Associados, 2006.

JOBIM e SOUZA, S. Infância e linguagem: Bakhtin, Vygotsky e Benjamin. 6.ed. São Paulo: Papirus, 2001.

KRAMER, S. A infância e sua singularidade. In: BRASIL. Ensino fundamental de nove anos: 
orientações para a inclusão da criança de seis anos de idade. Brasília: MEC/FNDE, 2006, p. 13-24.

LIMA, M. B. Identidades étnico-raciais, infância afro-brasileira e práticas escolares. In: ROCHA, E. A. C.; KRAMER, S. Educação infantil: enfoques em diálogo. São Paulo: Papirus, 2011, p. 139-156.

MANTOAN, M. T. E. Inclusão escolar: o que é? Por quê? Como fazer? São Paulo: Moderna, 2003.

MAZZOTTA, M. J. S. Educação especial no Brasil: história e políticas públicas. São Paulo: Cortez, 2001.MENDES, E. G. Perspectivas para a construção da escola inclusiva no Brasil. In: PALHARES, M. S.; MARINS, S. Escola Inclusiva. São Carlos: EduFSCar, 2002, p. 61-86.

OLIVEIRA, A. M. Professor é o eixo central na condução do trabalho pedagógico. Revista do Professor. Ano 14, n. 54, abr./jun. 1998.

PRIETO, R. G. Atendimento escolar de alunos com necessidades educacionais especiais: um olhar sobre as políticas públicas de educação no Brasil. In: ARANTES, V. A. (Org.). Inclusão escolar. São Paulo: Summus editorial, 2006.

ROCHA, E. A. C.; KRAMER, S. Educação infantil: enfoques em diálogo. São Paulo: Papirus, 2011. VICTOR, S. L. Inclusão escolar de crianças com necessidades educacionais especiais na educação infantil: concepções de professores regentes e especialistas em educação especial. In: VICTOR, S. L.; DRAGO, R.; CHICON, J. F. (Orgs.). A educação inclusiva de crianças, adolescentes, jovens e adultos: avanços e desafios. Vitória: EDUFES, 2010, p. 335-356.

A infância da criança com deficiência: uma revisão bibliográfica. In: VICTOR, S. L.; DRAGO, R.; CHICON, J. F. (Orgs.). Educação especial e educação inclusiva: conhecimentos, experiencias e formação. Araraquara: Junqueira\&Marin, 2011, p. 152-165.

VIGOTSKI, L. S. A formação social da mente. São Paulo: Martins Fontes, 1991.

. Psicologia pedagógica. São Paulo: Martins Fontes, 2001.

VIGOTSKII, L. S. La imaginación y el arte em la infância. Madri: Akal, 1996.

Recebido em novembro de 2011

Aprovado em maio de 2012

Rogério Drago, doutor em Educação pela Pontifícia Universidade Católica do Rio de Janeiro. Foi professor titular da Prefeitura Municipal de Vitória, atuando na educação infantil e anos iniciais do ensino fundamental. Atualmente é professor adjunto do Departamento de Teorias do Ensino e Práticas Educacionais e do Programa de Pós-Graduação em Educação do Centro de Educação da Universidade Federal do Espírito Santo. Publicação recente: Inclusão escolar e atendimento educacional especializado no contexto do projeto político pedagógico (Revista Brasileira de Política e Administração da Educação, v. 27, p. 433451, 2011). E-mail: rogerio.dragolagmail.com. 